\title{
Intravital imaging - dynamic insights into natural killer T cell biology
}

\section{Pei Xiong Liew and Paul Kubes* \\ Snyder Institute for Chronic Diseases, Cumming School of Medicine, University of Calgary, Calgary, AB, Canada}

Natural killer T (NKT) cells were first recognized more than two decades ago as a separate and distinct lymphocyte lineage that modulates an expansive range of immune responses. As innate immune cells, NKT cells are activated early during inflammation and infection, and can subsequently stimulate or suppress the ensuing immune response. As a result, researchers hope to harness the immunomodulatory properties of NKT cells to treat a variety of diseases. However, many questions still remain unanswered regarding the biology of NKT cells, including how these cells traffic from the thymus to peripheral organs and how they play such contrasting roles in different immune responses and diseases. In this new era of intravital fluorescence microscopy, we are now able to employ this powerful tool to provide quantitative and dynamic insights into NKT cell biology including cellular dynamics, patrolling, and immunoregulatory functions with exquisite resolution. This review will highlight and discuss recent studies that use intravital imaging to understand the spectrum of NKT cell behavior in a variety of animal models.

Edited by:

S. M. Mansour Haeryfar, Western University, Canada

Reviewed by: António Gil Castro,

University of Minho, Portugal Vasileios Bekiaris,

Danish Technical University, Denmark

${ }^{*}$ Correspondence:

Paul Kubes,

Snyder Institute for Chronic Diseases, Cumming School of Medicine,

University of Calgary, HRIC 4AA16, 3330 Hospital Drive NW, Calgary, $A B$

T2N 4N1, Canada

pkubes@ucalgary.ca

Specialty section:

This article was submitted to T Cell Biology, a section of the journal Frontiers in Immunology

Received: 01 April 2015 Accepted: 05 May 2015 Published: 20 May 2015

Citation:

Liew PX and Kubes P (2015) Intravital imaging - dynamic insights into

natural killer $T$ cell biology.

Front. Immunol. 6:240.

doi: 10.3389/fimmu.2015.00240
Keywords: natural killer $\mathrm{T}$ cells, intravital imaging, innate immunity, host-pathogen interactions, sterile

\section{Introduction}

Modern advances in technology have provided a plethora of in vitro and ex vivo methods to investigate the molecular systems and cellular functions of immune cells. These advances have resulted in significant insights into biological processes at the cellular level and deciphered multiple complex signaling pathways. Nevertheless, the most relevant experimental conditions in which to observe and document these biological processes remain the live animal. The use of intravital microscopy (IVM) provides such a view into the lives and dynamic interactions of diverse immune cell populations in various tissues and organs. Importantly, IVM is performed under experimental conditions which closely resemble the natural environment. As cellular functions and behaviors are influenced by several factors such as shear forces, anatomical location, and extracellular components, absence of these factors could result in tremendously different outcomes in in vitro versus in vivo settings.

Historically, IVM was first employed in the nineteenth century with brightfield microscopy to visualize leukocyte trafficking in translucent tissues (1). In the last two decades, brightfield-based IVM has brought about important discoveries especially in molecular and biophysical mechanisms of leukocyte adhesion to endothelial cells $(2,3)$. However, this basic technique applying visible light could only visualize uniformly colorless cells sufficiently slowed by adhesion, which allowed them to be distinguished from rapidly flowing cells (4). The advent of fluorescence-based intravital imaging with modern optical imaging agents and equipment now opens up exciting possibilities for biological observations. Many immune cells can now be tagged with fluorescent probes to visualize their behavior in real time in a live animal. Other important additions to fluorescence-based IVM are the inflammation 
different varieties of confocal microscopes, which provide deep tissue imaging and better subcellular resolution by excluding outof-focus light via point illumination and pinhole apertures $(5,6)$. For example, spinning disk confocal intravital imaging systems provide rapid image acquisitions at the expense of deep tissue imaging, and are extremely competent for dynamic observations of immune behavior and cell-cell interactions particular within the vasculature (7-9). In contrast, multiphoton microscope systems, which employ a pulsed infrared laser excitation to generate fluorescence, have allowed deep tissue imaging of cell-cell interactions up to $500 \mu \mathrm{m}$ depth $(10,11)$.

In recent years, fluorescence-based confocal IVM systems have been employed to visualize immune cells in almost all types of tissues to address a variety of immunological questions. Natural killer $\mathrm{T}(\mathrm{NKT})$ cells are credited with modulatory roles in a wide variety of diseases, and there is great interest in employing these cells for therapy in diseases or as biomarkers for prognostic purposes. In this review, we will focus on how IVM as a tool has revealed novel insights into NKT cell dynamics and biology.

\section{NKT Cells - A Quick Primer}

The name "NKT cell" was first conceived about 25 years ago, and was used to broadly define a subset of murine Tlymphocytes that shared functional and phenotypic characteristics with the natural killer cell, including the NK1.1 (NKR-P1 or CD161c) surface marker $(12,13)$. Although the term NKT cell is now accepted and applied to these cells in both mice and humans, this definition is inaccurate and possibly misleading as NKT cells in certain mouse strains do not express NK1.1 due to the allelic divergence of NK1.1 genes $(14,15)$. To further complicate this classification, some conventional $\mathrm{T}$ cells have been described to spontaneously express NK1.1 after activation (16).

Around the time when NKT cells were identified, a novel process of presenting lipid antigens was discovered $(17,18)$. This antigen presentation process occurred through the MHC class Ilike molecule designated as CD1 (cluster of differentiation 1) that includes CD1a-CD1e $(19,20)$. All of these CD1 molecules present lipids instead of peptides as antigens. While humans express all five CD1 genes, mice express only CD1d. In mammals, CD1d is highly conserved (21). Further studies in mice subsequently demonstrated that CD1d molecules presented lipids to invariant T cell receptor (TCR)-bearing cells, which also expressed NK1.1 (22-24). This finding led to the realization that NKT cells were reactive to CD1d, and that the invariant TCR $\alpha$-chain and CD1d were essential for the development of NKT cells. These unique phenotypic characteristics are now used to define NKT cells. An excellent review highlights the detailed timeline of discoveries that contributed to the identification of NKT cells (12).

The discovery of the compound $\alpha$-galactosylceramide ( $\alpha$ GalCer) in 1997 contributed greatly to the understanding of NKT cells (25). This potent and specific lipid antigen, isolated from a marine sponge sample (likely from an infecting proteobacterium), was the first identified antigen for a specific population of NKT cells termed Type I NKT cells or invariant NKT (iNKT) cells. Through the use of CD1d tetramers loaded with $\alpha \mathrm{GalCer}$, iNKT cells in mice were discovered to express the invariant V $\alpha 14-\mathrm{J} \alpha 18$ TCR $\alpha$-chain paired with a $\beta$-chain biased toward V $\beta 2, \mathrm{~V} \beta 3$, and $\mathrm{V} \beta 8(26,27)$. More than $80 \%$ of NKT cells were found to express these invariant chains. A similar TCR limited repertoire was found in human iNKT cells, which expressed V $\alpha 24-J \alpha 18$ paired with the V $\beta 11$ chain (28). Due to large structural and functional similarities between the TCRs expressed by human and mice iNKT cells, $\alpha$ GalCer can bind to and activate iNKT cells from both species (29). In fact, this property has been taken advantage of by researchers to develop multimeric molecules with loaded synthetic $\alpha$ GalCer to identify iNKT cells ex vivo (30). These synthetic loaded tetramers are used in conjunction with anti-CD3 or anti-TCR $\beta$ antibodies to identify and enumerate iNKT cells in multi-parameter flow cytometry. In addition to $\alpha \mathrm{GalCer}$, a considerable number of exogenous ligands have been identified to activate iNKT cells (31). Further, self-derived endogenous lipids as well as the cytokines interleukin (IL)-12 and IL-18 have also been described to activate iNKT cells $(32,33)$. As iNKT cells can be activated by a range of exogenous and endogenous antigens and diverse inflammatory stimuli (Figure 1), they were found to be more important than initially realized in a variety of diseases $(34,35)$. Apart from Type I NKT cells, another subset of NKT cells has also been described (36-38). These Type II NKT cells recognize lipid antigens but express diverse TCR $\alpha$ - and $\beta$-chains $(39,40)$ and do not recognize $\alpha \mathrm{GalCer}(41,42)$. As this group of NKT cells cannot be identified through $\alpha$ GalCer-loaded CD1d tetramers, they are comparatively less characterized and understood (as compared to iNKT cells). This review shall focus mainly on findings discovered in mouse and human iNKT cell studies.

Although iNKT cells develop in the thymus, they are generally categorized as innate lymphocytes because iNKT cells exist in a poised effector state when they mature. Accordingly, mature iNKT cells are able to rapidly release large quantities of proinflammatory $\mathrm{T}$ helper type $1\left(\mathrm{~T}_{\mathrm{H}} 1\right)$ [(for example, interferon- $\gamma$ (IFN- $\gamma$ )] or $\mathrm{T}$ helper type $2\left(\mathrm{~T}_{\mathrm{H}} 2\right)$ (IL-4 and IL-10) cytokines within hours of activation $(43,44)$. In mice, resting iNKT cells contain preformed mRNA for both IFN- $\gamma$ and IL-4 to allow swift cytokine production (45). These cytokines are able to transactivate other immune cells including neutrophils, NK cells, dendritic cells, and macrophages during an immune response $(15,46)$. Because iNKT cells are able to rapidly release substantial quantities of cytokines that can polarize the immune response, they are hypothesized to be important orchestrators of immunity. For example, activation of iNKT cells during infection results in the secretion of pro-inflammatory cytokines, which stimulates the developing immune response to fight off microbial invaders (4749). A similar protective effect of iNKT cells is also observed during cancer $(50,51)$. On the other hand, iNKT cells can strengthen immuno-suppressive pathways during autoimmunity or ischemia-reperfusion injuries such as stroke $(52,53)$. In a mouse stroke model, there is increased sympathetic drive which induces iNKT cells to make more IL-10 and less IFN- $\gamma$ (8). This leads to overall immuno-suppression but places individuals at a greater risk to infections. iNKT cells are therefore pivotal in shaping immune responses during diverse pathological states. An ongoing challenge is to unravel the factors that determine if iNKT cells facilitate or suppress an immune response. 


\section{A Exogenous antigen}

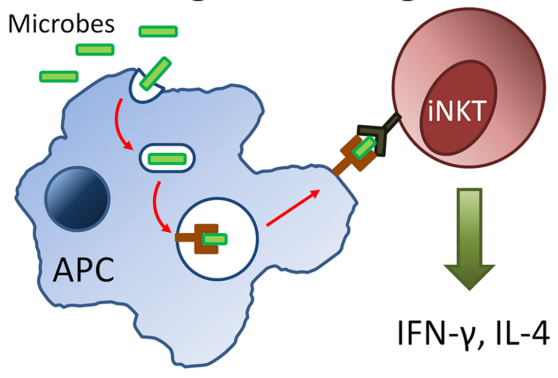

c Cytokine and self-antigen

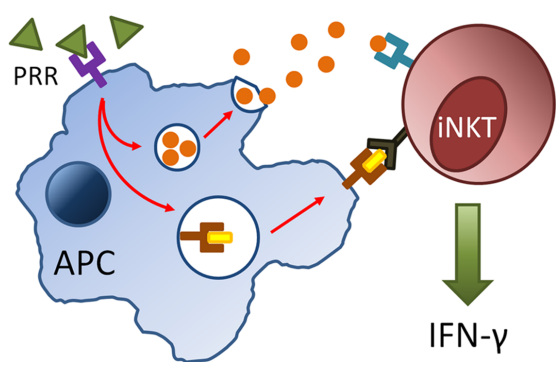

FIGURE 1 | Pathways of invariant natural killer T (iNKT) cell activation during infection and injury. (A) Antigen-presenting cells (APCs) engulf invading microbes during infection and present exogenous antigens via CD1d molecules directly to the T cell receptor (TCR) on iNKT cells. (B) Injury to the central nervous system (CNS) results in signals transmitted via neurones and release of neurotransmitters such as noradrenaline. These neutrotransmitters bind to adrenergic receptors on iNKT cells resulting in their activation.

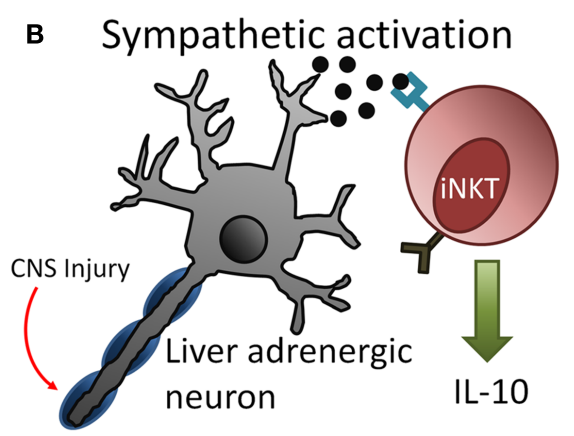

D Cytokines only activation

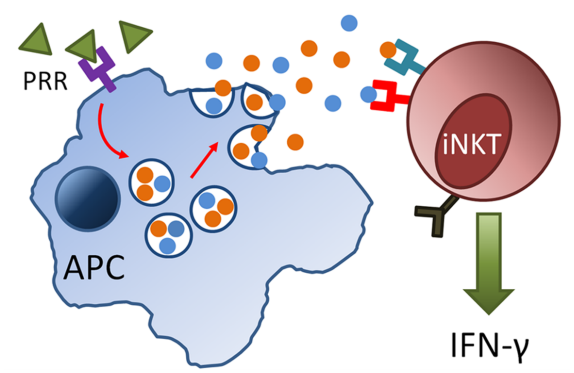

(C,D) During infection and injury, pathogen-associated molecular patterns (PAMPs) or damage-associated molecular patterns (DAMPs) are released. These PAMPs and DAMPs bind to pattern-recognition receptors (PRRs) on APCs, which result in the production of inflammatory cytokines such as interleukin-12 and presentation of self-antigens on CD1d to the TCR of iNKT cells. The synergy of cytokine or self-antigen presentation contributing to iNKT cell activation depends on the type of injury or microbe involved during infection.
Thus far, iNKT cells have been described to produce IL-2, IL-5, IL-6, IL-10, IL-13, IL-17, IL-21, tumor necrosis factor- $\alpha$, transforming growth factor- $\beta$, and granulocyte monocyte-colonystimulating factor $(15,54,55)$. How does a single population of cells produce such a large variety of cytokines? The type and quantity of cytokine produced is influenced by several non-mutually exclusive factors. First, the quality of TCR signal (i.e., antigen signal strength and CD1d-binding kinetics) affects the cytokine profile. For example, use of different $\alpha \mathrm{GalCer}$ analogs have been described to result in different ratios of IFN- $\gamma /$ IL-4 produced (5658). A similar phenomenon should occur with endogenous antigens compared to relevant foreign antigens. Second, targeting of antigen to different antigen-presenting cells will alter the pattern of cytokines made by iNKT cells $(59,60)$. Finally, functionally different subsets of iNKT cells have been described based on tissue localization and cell surface phenotype, which may promote different outcomes when iNKT cells are activated $(15,61)$.

\section{Imaging iNKT Cells}

There are a multitude of publications that describe the activation and cytokine production profiles of iNKT cells in mice and humans. However, their tissue distribution and dynamic behavior have only been brought to light recently. The capacity to visualize and observe iNKT cell behavior relies considerably on the labeling method. To date, no lineage-specific fluorescent antibody has been able to label iNKT cells. Isolating iNKT cells and staining them ex vivo with a fluorescent dye (for example, carboxyfluorescein diacetate succinimidyl ester) for adoptive transfer provides a manner to observe their behavior in an organ (62). However, this opens the possibility that cellular behavior may be altered by the potential artifact of cell isolation. So far, the best avenue is the use of genetically engineered knock-in mice where fluorescent proteins are inserted into a lineage-specific gene locus (63). Both mouse and human iNKT cells express high levels of the Cxcr6 chemokine receptor, which has been demonstrated to mediate the survival of iNKT cells in the liver (64-66). To image iNKT cells in a live animal, a mouse containing enhanced green fluorescent protein (GFP) inserted into the Cxcr6 gene $\left(C x c r 6^{G f p /+}\right)$ was generated (67). iNKT cells have been found to account for $75-80 \%$ of all GFP $^{\text {bright }}$ cells in the liver. For the first time, the dynamic behavior of iNKT cells in different tissues and organs could be observed. Using IVM, hepatic iNKT cells were seen to crawl along the luminal side of liver sinusoidal endothelial cells without directional bias with an average speed of $10 \mu \mathrm{m} / \mathrm{min}$ (Figure 2A) (9, 67). This distinct behavior is unlike leukocyte behavior observed in post-capillary venules where leukocytes roll along continuous endothelium $(3,68)$. Detailed analysis of iNKT cell behavior in the liver demonstrated that iNKT cell crawling was random and independent of blood flow (67).

Resident iNKT cells are enriched in the liver, comprising up to $30 \%$ of all lymphocytes as compared to the thymus, lung, colon, bone marrow, spleen, lymph nodes, and blood (44). The cause for the higher frequency of resident iNKT cells in the liver is 

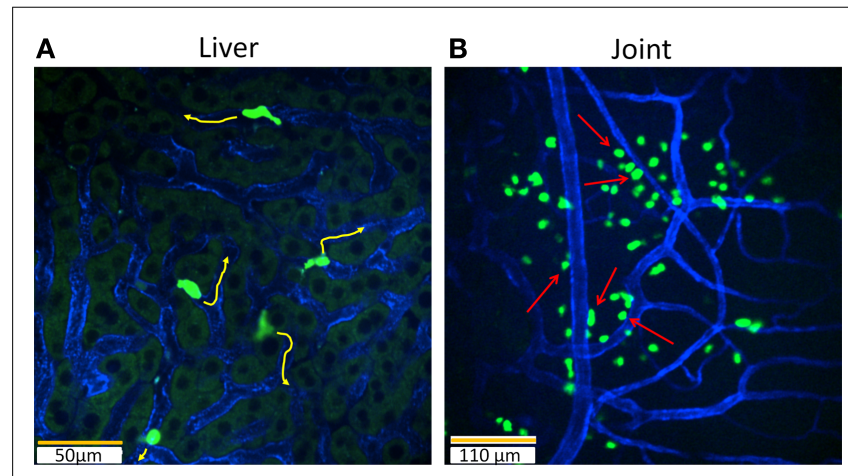

FIGURE 2 | Intravital imaging of iNKT cells in the liver and joints with Cxcr6 $^{\text {Gfp/ }+}$ mice. Still snapshots of videos recorded during imaging in a live animal are presented in: (A) iNKT cells (bright green) in the liver are intravascular and crawl on the luminal side of liver sinusoidal endothelial cells (blue) under basal conditions. When iNKT cells are activated, they no longer crawl and instead slow down their crawling phenotype or completely arrest. $20 \times$ objective, scale bar $50 \mu \mathrm{m}$. (B) In contrast, iNKT cells (bright green) in the joint are extravascular and line the capillaries (blue). These iNKT cells do not crawl and are stationary. During pathogen invasion in the joint, as in the case of $B$. burgdorferi, iNKT cells begin to crawl along vessel walls. Joint iNKT cells limit the dissemination of bacteria. Arrows: iNKT cells lining the vasculature. $10 \times$ objective, scale bar $110 \mu \mathrm{m}$.

not completely clear; however, the adhesion molecule leukocyte function-associated antigen-1 (LFA-1, CD11a) has been suggested to be important in retaining iNKT cells in the liver (69). A tandem blockade of LFA-1 and its corresponding ligand, intercellular adhesion molecule 1 (ICAM-1), created a substantial rise in iNKT cells in blood and a reciprocal decrease in their number in the liver. Furthermore, LFA-1-deficient mice have notably reduced numbers of iNKT cells in the liver (70). Although we observed that the crawling phenotype of iNKT cells in liver sinusoids was not affected by LFA-1 and ICAM-1 antibodies, they did detach in collecting venules after treatment with blocking antibodies (71). Taken together, these data indicate that LFA-1 and ICAM-1 were perhaps necessary for interactions in larger vessels but not for crawling in sinusoids.

Previous studies have demonstrated that $\mathrm{T}$ cells arrest their movement when they encounter cognate antigen $(72,73)$. iNKT cells in the liver exhibit a similar behavior; when $\alpha$ GalCer was injected intravenously, crawling GFP ${ }^{\text {bright }}$ iNKT cells became stationary within an hour (67). Other studies have shown that hepatic iNKT cell arrest was correlated with iNKT cell activation $(8,9)$. Activation of iNKT cells via various mechanisms including CD1d, cytokines, or even neurotransmission all induce cell arrest within liver sinusoids. For example, synergistic effects between the inflammatory cytokines IL-12 and IL-18 resulted in the arrest of hepatic iNKT cells (74). In a mouse stroke model, norepinephrine release by the sympathetic nervous system during stroke caused rapid arrest of iNKT cells in the liver (8). Hepatic iNKT cells have been shown to express adrenergic receptors to receive neural signals (75). When iNKT cells are activated through cytokines or noradrenergic receptors, blockade of CD1d had no effect on the arrest of iNKT cells which suggests that classical antigen presentation through CD1d did not play a major role in arrest and activation in these situations.

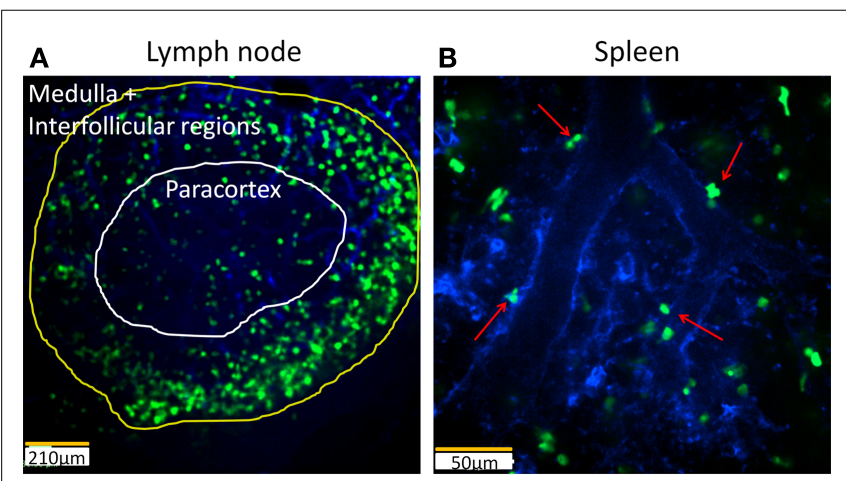

FIGURE 3 | Intravital imaging of iNKT cells in the lymph node and spleen of Cxcr6 $^{\text {Gfp/ }}+$ mice. (A) Still image demonstrating distribution of iNKT cells (bright green) in different regions of a lymph node. Vasculature of the lymph node is labelled with PECAM-1 (blue). The medullar and interfollicular regions are outlined in yellow while the paracortex is outlined in white. $10 \times$ objective, scale bar $210 \mu \mathrm{m}$. (B) Still snapshot of splenic iNKT cells (bright green) in red pulp of spleen reveals that these cells are located outside the vasculature (blue). Arrows: extravascular iNKT cells. $20 \times$ objective, scale bar $50 \mu \mathrm{m}$.

Despite the fact that the frequency of iNKT cells in other organs than the liver is low, various studies have highlighted the importance of iNKT cells in these organs in response to blood-borne pathogens (76-78). The Cxcr6 $6^{G p /+}$ mouse has been employed to study the spatial organization, behavior, and functional roles of iNKT cells in several organs including the joints, lymph node, spleen, and lung. In distinct contrast to the liver, intravital imaging of iNKT cells in joints revealed dramatic localization of these cells around the joint blood vessels but not inside the vessels (Figure 2B) (78). Joint iNKT cells also exhibited different behavior under basal conditions as they were stationary and non-motile. In the lymph node, iNKT cells are located in the medulla and the interfollicular region but mainly absent in the deep paracortex where naïve T cells reside (Figure 3A) (79). These iNKT cells are highly motile in the lymph node and actively communicate with resident subcapsular sinus macrophages. During systemic infection, resident macrophages produce IL-18 and complementary cytokines, which elicit an innate IFN- $\gamma$ response from lymph node iNKT cells. On the other hand, iNKT cells were found to be widely distributed throughout the spleen, including B and T cell follicles in the periarteriolar lymphoid sheath, the marginal zone (MZ), as well as the red pulp $(69,76,80)$. Dissimilar to the liver, iNKT cells were observed to be crawling outside the vasculature in the spleen (Figure 3B) $(71,76)$. Interestingly, the localization of iNKT cells changes in the spleen during infection or in the presence of cognate lipid antigens. Under these conditions, iNKT cells slow down or arrest, and are confined to the $\mathrm{MZ}$ where antigen-rich MZ macrophages and dendritic cells reside $(76,80)$.

Although there is evidence demonstrating that iNKT cells are important in allergy and airway inflammation, information on the anatomical distribution of iNKT cells in lung, their mechanism of activation, and role in lung diseases remain scarce $(77,81)$. Recent studies have attempted to address these questions. Two-photon fluorescence microscopy was employed to examine the localization of iNKT cells in a harvested lobe of a murine lung (82). They 
revealed that pulmonary iNKT cells mainly resided in the lung microvasculature. Upon exposure to aerosolized lipid antigen, iNKT cells mobilized and extravasated into lung tissue. Thomas et al. (69) showed that there was an approximate 10- to 20-fold enrichment of iNKT cells in blood drawn from the right or left ventricles of the heart as compared to peripheral blood. Another study suggests that some pulmonary iNKT cells can be longlived (83). Using parabiotic mice, Bendelac and colleagues demonstrated that pulmonary iNKT cells do not recirculate between parabiotic mice pairs even after 30 days (69).

\section{Interactions Between the Host and Pathogens}

Although $\alpha$ GalCer was extracted from a marine sponge sample, the presence of this iNKT cell ligand in marine sponges was not linked to any physiological relevant function. This highly reactive glycolipid likely originated from a bacterium present inside the sample rather than the sponge itself as marine sponges are commonly colonized by $\alpha$-proteobacteria such as Sphingomonas spp. $(84,85)$. Indeed, the physiologically relevant $\alpha$ GalCer-related compounds, $\alpha$-glycuronylceramide, and $\alpha$-galacturonosylceramide which are found in the cell wall of Sphingomonas, are strong and potent activators of iNKT cells (48, $49,86,87)$. In addition to ceramide-based compounds from Sphingomonas, glycerol-based lipids have been described to potently activate iNKT cells. These include $\alpha$-galactosyldiacylglycerol from Borrelia burgdorferi and $\alpha$-glucosyldiacylglycerol from Streptococcus pneumoniae $(88,89)$.

Borrelia burgdorferi is a spirochete pathogen that continues to spread in North America (90). This pathogen induces Lymedisease, and delayed or inadequate treatment typically leads to disabling symptoms as the bacteria invade the joints, heart, and central nervous system (91). The liver functions as an important organ that is positioned to intercept disseminating pathogens in the blood (92). This interception is mediated by liverresident intravascular macrophages (Kupffer cells), which ensnare pathogens from the blood stream. Visualizing iNKT cell activity in the liver showed dramatically altered iNKT cell behavior after B. burgdorferi infection (9). Instead of crawling through the liver sinusoids, iNKT cells formed clusters and arrested next to Kupffer cells that had captured B. burgdorferi. This clustering occurred as early as $4 \mathrm{~h}$ after exposure and could be inhibited by blocking the Cxcr3 receptor. Anti-CD1d antibody blocked the firm adhesion of iNKT cells to Kupffer cells as well as the activation of iNKT cells, which suggests that Kupffer cells were responsible for presenting antigens to activate iNKT cells. Intravital imaging during this process revealed that Kupffer cells phagocytose B. burgdorferi from blood for antigen presentation to iNKT cells, which then produce IFN- $\gamma$ and other inflammatory cytokines. This activated the local hepatic innate immunity system to prevent bacteria dissemination.

The absence of iNKT cells in mice caused a remarkable 25fold increase in $B$. burgdorferi burden in joints, but other organs did not have a similar burden, which indicated that iNKT cells in the joint microenvironment had a unique feature. This unique in vivo observation led investigators to question the functional significance of joint iNKT cells. Intravital imaging of the joint during $B$. burgdorferi infection revealed that extravascular iNKT cells interact directly with the spirochetes at joint blood vessel walls (78). This joint iNKT cell behavior was in distinct contrast to iNKT cells in the liver, which were oblivious to the pathogen in the absence of Kupffer cells. During this interaction, joint iNKT cells were no longer stationary but actively crawled along vessel walls toward the pathogen, perhaps due to complement activation. $B$. burgdorferi that interacted with iNKT cells subsequently died, which suggests that joint iNKT cells limit the dissemination of this pathogen into the joint. Indeed, absence of iNKT cells led to a large number of motile spirochetes outside the vasculature in the joint cavity of mice. It is worth noting that human joints had far fewer iNKT cells, and perhaps this may lead to the susceptibility of humans, but not mice, to B. burgdorferi-induced Lyme arthritis.

Streptococcus pneumoniae infection is a leading cause of morbidity and mortality in adults and children $(93,94)$. This encapsulated bacteria typically resides on the mucosal surface of the upper respiratory tract or the nasopharynx of humans and appears to be asymptomatic (95). However, if S. pneumoniae gains access to the sterile lower respiratory tract, it causes a potent inflammatory response that result in severe disease. In this situation, pulmonary iNKT cells are important in the protection of the host against an infection by $S$. pneumoniae (96). If iNKT cells are absent (in J $\alpha 18^{-1-}$ mice) following infection by S. pneumoniae, lower cytokine levels, less neutrophils, and increased bacteria burden were found in the lung. The iNKT cell-deficient mice also had increased mortality following $S$. pneumoniae infection. A recent paper demonstrated that this protective effect was dependent on recognition of a $S$. pneumoniae glycoplipid (89). The behavior of iNKT cells in the lung under basal and $S$. pneumoniae infection has not been fully elucidated due to challenges of imaging the lung. Moreover, it is unclear which immune cells are presenting S. pneumoniae glycolipids to iNKT cells. Clearly, it would be of benefit to examine the dynamics of iNKT cells in the lung under these different conditions.

Other naturally occurring microbial antigens including cholesterol ester from Helicobacter pylori (97), lipopeptidophosphoglycans from Leishmania donovani (98), and Entameba histolytica (99) can activate iNKT cells, but the antigenicity of these lipids are not well characterized and direct evidence of significant contribution of these lipid antigens during infection and disease remain elusive. Further study is necessary to determine their contribution to the activation of iNKT cells during these specific infections.

\section{The Balance Between Regulating Inflammation After Tissue Injury Versus Host Defense}

The inflammatory response is critical for host defense against invading pathogens. Known as sterile inflammation, inflammation also occurs when self tissue is damaged in the absence of infection (100). Akin to inflammation induced by microbes, sterile inflammation also results in recruitment of neutrophils, monocytes, and macrophages, and the release of chemokines and pro-inflammatory cytokines such as IL-1 (101). Sterile inflammation has been identified to underlie many medical afflictions such as burn injuries or ischemia-reperfusion injury in the heart, liver, and brain (102). Following the initial trauma, the outcome of these 
afflictions are immunosuppression and susceptibility of the host to subsequent infection. Some medical examples of these complications include patients with acute myocardial infarction, stroke, or major burn injuries. Systemically inhibiting inflammation in these conditions can lead to adverse infectious complications. With the ability to react to self or invasive pathogens, iNKT cells are the linchpins which can determine a favorable or detrimental outcome during inflammation in these conditions.

Able to respond to "self" lipid antigens, iNKT cells are able to regulate inflammation during tissue injury $(46,103)$. Several endogenous lipids have been proposed to activate iNKT cells, although identification of the primary endogenous lipid antigen is a subject of intense research (104-106). Nevertheless, during tissue injury and cell death, endogenous antigens can serve as danger signals to activate iNKT cells in the absence of exogenous ligands. The functional role of iNKT cells have been investigated in mouse models of burn injury. In a cauterization-induced corneal inflammation model, iNKT cell-deficient mice had increased neutrophil accumulation and higher levels of pro-inflammatory cytokines in the cauterized eye (107). In addition, lack of iNKT cells led to greater corneal edema and opacity. In this model, iNKT cells played an important role in curbing inflammation and maintained corneal clarity. A similar immunoregulatory effect was observed in a dorsal burn injury model where iNKT cells were found to mediate T cell proliferation after injury by producing IL-4 (108). Production of IL-4 by iNKT cells suppressed antigen-specific $\mathrm{T}$ cell delayed-type hypersensitivity after dorsal burn injury.

During stroke, intravital imaging revealed that norepinephrine release rapidly arrested and activated iNKT cells in the liver (8). Interestingly, this increased sympathetic drive induced activated iNKT cells to produce increased levels of anti-inflammatory cytokines such as IL-10, which led to post-stroke immunosuppression. This effect likely protects the brain from inflammatory damage (109) but also leaves the patient open to infection, which is a major cause of post-stroke death (110). In contrast, activating iNKT cells with the potent agonist $\alpha$ GalCer reduced bacterial infection after stroke (8). Collectively, these findings suggest that iNKT cell activation was not the determining factor that mediated immunosuppression after stroke but rather the adrenergic activation and modulation of iNKT cells resulted in a shift from proinflammatory to anti-inflammatory cytokine production. This also raises the possibility of therapeutically targeting iNKT cells in the liver to quench detrimental neuro-immunosuppression as long as it does not enhance inflammation in the brain.

\section{Concluding Remarks}

There is no doubt that iNKT cells have a pivotal function in directing innate and adaptive immunity during diseases where their diverse effector repertoire can lead to varied outcomes ranging from promoting inflammation to immunosuppression. Despite recent advances in unraveling mechanisms of iNKT cell activation and a greater understanding of iNKT cell biology, more research to elucidate the interactions between iNKT cells and other leukocytes is still needed. Traditionally, visualizing the spatial distribution of iNKT cells and understanding the role of iNKT cells in context of other immune cells were through static snapshots of tissue sections. However, technological advances in fluorescence microscopy and maturation of IVM technology have revolutionized the iNKT cell research field, allowing us to image the behavior of these cells in different organs under basal and inflammatory conditions at high resolution.

Although the ability to accurately visualize cells in a live animal at microscopic scale provides exciting opportunities for biological observation, caution is still needed at this stage. Fluorescence IVM is dependent on labeling cell types, and current technology is restricted by an inability to label all cell types, structural components, and chemical mediators at the same time. Therefore, only visible cell-cell interactions can be observed. In addition, the reporter mice that are presently available for lineage specific cell types including the $C x c r 6^{G f p /+}$ mice are not entirely specific and in some organs like the intestines, the percentage of GFP-positive cells that are iNKT cells is $<50 \%$, which makes it impossible to specifically track these cells. Further, current limitations of IVM technologies do not allow high-resolution imaging of all tissues and for those that can be visualized, it may not be possible to image deep into the tissue. Ongoing improvements to IVM technology such as the use of multiphoton microscopes, far-red probes, and longer wavelength lasers would address some of these issues (5, 10). Finally, current IVM techniques do not allow large areas of the tissue to be scanned at quick speeds; this limits imaging to relatively slower dynamic processes for observation if macroscopic levels are desired. Nevertheless, a thorough understanding of the spectrum of iNKT cell behavior and mechanisms of action will occur as IVM technology improves. Understanding iNKT cell biology will ultimately determine our ability to successfully target iNKT cells for clinical applications.

\section{Outstanding Questions}

1. What factors determine the outcome, inflammation versus immunosuppression, of iNKT cell activation during diverse pathological states?

2. What are the roles of iNKT cells in the context of other immune cells under basal and inflammatory states?

3. How does the location and behavior of iNKT cells in the liver differ from other organs (such as the spleen, lung, and intestine)? Are there any similarities?

4. How can an enhanced understanding of the spectrum iNKT cell biological behaviors be utilized to manipulate their function for clinical settings?

5. Are iNKT cell counts and roles altered during pathological states? Are they reversible and does it affect the therapeutic ability of iNKT cells?

\section{Acknowledgments}

We would like to thank Woo-Yong Lee, Justin Deniset, and Ania Zuba for contributing joint, spleen, and lymph node images of NKT cells. Our work is supported by the Canadian Institutes for Health Research operating grants as well as the Canadian Foundation for Innovation. PK is an Alberta Innovates Health Solutions Scientist and the Snyder Chair in Critical Care Medicine; PXL is supported by Alberta Innovates Health Solutions studentship. 


\section{References}

1. Wagner R. Erlauterungstaflen zur Physiologie und Entwicklungsgeschichte. Leipzig: Leopold Voss (1839).

2. Wagner DD, Frenette PS. The vessel wall and its interactions. Blood (2008) 111(11):5271-81. doi:10.1182/blood-2008-01-078204

3. Petri B, Phillipson M, Kubes P. The physiology of leukocyte recruitment: an in vivo perspective. J Immunol (2008) 180(10):6439-46. doi:10.4049/ jimmunol.180.10.6439

4. Mempel TR, Scimone ML, Mora JR, von Andrian UH. In vivo imaging of leukocyte trafficking in blood vessels and tissues. Curr Opin Immunol (2004) 16(4):406-17. doi:10.1016/j.coi.2004.05.018

5. Ntziachristos V. Going deeper than microscopy: the optical imaging frontier in biology. Nat Methods (2010) 7(8):603-14. doi:10.1038/nmeth.1483

6. Pittet MJ, Weissleder R. Intravital imaging. Cell (2011) 147(5):983-91. doi:10. 1016/j.cell.2011.11.004

7. McDonald B, Pittman K, Menezes GB, Hirota SA, Slaba I, Waterhouse CC, et al. Intravascular danger signals guide neutrophils to sites of sterile inflammation. Science (2010) 330(6002):362-6. doi:10.1126/science.1195491

8. Wong CHY, Jenne CN, Lee WY, Leger C, Kubes P. Functional innervation of hepatic iNKT cells is immunosuppressive following stroke. Science (2011) 334(6052):101-5. doi:10.1126/science.1210301

9. Lee WY, Moriarty TJ, Wong CH, Zhou H, Strieter RM, van Rooijen N, et al. An intravascular immune response to Borrelia burgdorferi involves kupffer cells and iNKT cells. Nat Immunol (2010) 11(4):295-302. doi:10.1038/ ni. 1855

10. Ishii T, Ishii M. Intravital two-photon imaging: a versatile tool for dissecting the immune system. Ann Rheum Dis (2011) 70(Suppl 1):i113-5. doi:10.1136/ ard.2010.138156

11. Helmchen F, Denk W. Deep tissue two-photon microscopy. Nat Methods (2005) 2(12):932-40. doi:10.1038/nmeth818

12. Godfrey DI, MacDonald HR, Kronenberg M, Smyth MJ, Van Kaer L. NKT cells: what's in a name? Nat Rev Immunol (2004) 4(3):231-7. doi:10.1038/ nri1309

13. Bendelac A, Rivera MN, Park SH, Roark JH. Mouse CD1-specific NK1 T cells: development, specificity, and function. Annu Rev Immunol (1997) 15:535-62. doi:10.1146/annurev.immunol.15.1.535

14. Carlyle JR, Mesci A, Ljutic B, Belanger S, Tai LH, Rousselle E, et al. Molecular and genetic basis for strain-dependent NK1.1 alloreactivity of mouse NK cells. J Immunol (2006) 176(12):7511-24. doi:10.4049/jimmunol.176.12.7511

15. Brennan PJ, Brigl M, Brenner MB. Invariant natural killer T cells: an innate activation scheme linked to diverse effector functions. Nat Rev Immunol (2013) 13(2):101-17. doi:10.1038/nri3369

16. Slifka MK, Pagarigan RR, Whitton JL. NK markers are expressed on a high percentage of virus-specific CD8+ and CD4+ T cells. J Immunol (2000) 164(4):2009-15. doi:10.4049/jimmunol.164.4.2009

17. Porcelli S, Morita CT, Brenner MB. CD1b restricts the response of human CD4-8- T lymphocytes to a microbial antigen. Nature (1992) 360(6404):593-7. doi: $10.1038 / 360593 \mathrm{a} 0$

18. Beckman EM, Porcelli SA, Morita CT, Behar SM, Furlong ST, Brenner MB. Recognition of a lipid antigen by CD1-restricted alpha beta+ T cells. Nature (1994) 372(6507):691-4. doi:10.1038/372691a0

19. Brigl M, Brenner MB. CD1: antigen presentation and T cell function. Annu Rev Immunol (2004) 22:817-90. doi:10.1146/annurev.immunol.22.012703.104608

20. Cohen NR, Garg S, Brenner MB. Antigen presentation by CD1 lipids, T cells, and NKT cells in microbial immunity. Adv Immunol (2009) 102:1-94. doi:10. 1016/S0065-2776(09)01201-2

21. Barral DC, Brenner MB. CD1 antigen presentation: how it works. Nat Rev Immunol (2007) 7(12):929-41. doi:10.1038/nri2191

22. Bendelac A, Lantz O, Quimby ME, Yewdell JW, Bennink JR, Brutkiewicz RR. CD1 recognition by mouse NK1+ T lymphocytes. Science (1995) 268(5212):863-5. doi:10.1126/science.7538697

23. Bendelac A. Positive selection of mouse NK1+ T cells by CD1-expressing cortical thymocytes. J Exp Med (1995) 182(6):2091-6. doi:10.1084/jem.182.6. 2091

24. Exley M, Garcia J, Balk SP, Porcelli S. Requirements for CD1d recognition by human invariant Valpha24+ CD4-CD8- T cells. J Exp Med (1997) 186(1):109-20. doi:10.1084/jem.186.1.109
25. Kawano T, Cui J, Koezuka Y, Toura I, Kaneko Y, Motoki K, et al. CD1d-restricted and TCR-mediated activation of valpha14 NKT cells by glycosylceramides. Science (1997) 278(5343):1626-9. doi:10.1126/science.278. 5343.1626

26. Benlagha $K$, Weiss A, Beavis A, Teyton L, Bendelac A. In vivo identification of glycolipid antigen-specific T cells using fluorescent CD1d tetramers. J Exp Med (2000) 191(11):1895-903. doi:10.1084/jem.191.11.1895

27. Matsuda JL, Naidenko OV, Gapin L, Nakayama T, Taniguchi M, Wang CR, et al. Tracking the response of natural killer $\mathrm{T}$ cells to a glycolipid antigen using CD1d tetramers. J Exp Med (2000) 192(5):741-53. doi:10.1084/jem.192.5.741

28. Dellabona P, Padovan E, Casorati G, Brockhaus M, Lanzavecchia A. An invariant $\mathrm{V}$ alpha 24-J alpha Q/V beta $11 \mathrm{~T}$ cell receptor is expressed in all individuals by clonally expanded CD4-8- T cells. J Exp Med (1994) 180(3):1171-6. doi:10. 1084/jem.180.3.1171

29. Brossay L, Chioda M, Burdin N, Koezuka Y, Casorati G, Dellabona P, et al. CD1d-mediated recognition of an alpha-galactosylceramide by natural killer T cells is highly conserved through mammalian evolution. J Exp Med (1998) 188(8):1521-8. doi:10.1084/jem.188.8.1521

30. Liu Y, Goff RD, Zhou D, Mattner J, Sullivan BA, Khurana A, et al. A modified alpha-galactosyl ceramide for staining and stimulating natural killer $\mathrm{T}$ cells. J Immunol Methods (2006) 312(1-2):34-9. doi:10.1016/j.jim.2006.02.009

31. Rossjohn J, Pellicci DG, Patel O, Gapin L, Godfrey DI. Recognition of CD1d-restricted antigens by natural killer T cells. Nat Rev Immunol (2012) 12(12):845-57. doi:10.1038/nri3328

32. Lawson V. Turned on by danger: activation of CD1d-restricted invariant natural killer T cells. Immunology (2012) 137(1):20-7. doi:10.1111/j.1365-2567. 2012.03612.x

33. Reilly EC, Wands JR, Brossay L. Cytokine dependent and independent iNKT cell activation. Cytokine (2010) 51(3):227-31. doi:10.1016/j.cyto.2010.04.016

34. Berzins SP, Smyth MJ, Baxter AG. Presumed guilty: natural killer T cell defects and human disease. Nat Rev Immunol (2011) 11(2):131-42. doi:10. 1038/nri2904

35. Berzins SP, Ritchie DS. Natural killer T cells: drivers or passengers in preventing human disease? Nat Rev Immunol (2014) 14(9):640-6. doi:10.1038/ nri3725

36. Behar SM, Podrebarac TA, Roy CJ, Wang CR, Brenner MB. Diverse TCRs recognize murine CD1. J Immunol (1999) 162(1):161-7.

37. Cardell S, Tangri S, Chan S, Kronenberg M, Benoist C, Mathis D. Cd1restricted Cd4(+) T-cells in major histocompatibility complex class Ii-deficient mice. J Exp Med (1995) 182(4):993-1004. doi:10.1084/jem.182.4.993

38. Park SH, Roark JH, Bendelac A. Tissue-specific recognition of mouse CD1 molecules. J Immunol (1998) 160(7):3128-34.

39. Arrenberg P, Halder R, Dai Y, Maricic I, Kumar V. Oligoclonality and innatelike features in the TCR repertoire of type II NKT cells reactive to a beta-linked self-glycolipid. Proc Natl Acad Sci U S A (2010) 107(24):10984-9. doi:10.1073/ pnas. 1000576107

40. Park SH, Weiss A, Benlagha K, Kyin T, Teyton L, Bendelac A. The mouse CD1d-restricted repertoire is dominated by a few autoreactive $\mathrm{T}$ cell receptor families. J Exp Med (2001) 193(8):893-904. doi:10.1084/jem.193.8.893

41. Blomqvist M, Rhost S, Teneberg S, Lofbom L, Osterbye T, Brigl M, et al. Multiple tissue-specific isoforms of sulfatide activate CD1d-restricted type II NKT cells. Eur J Immunol (2009) 39(7):1726-35. doi:10.1002/eji.200839001

42. Jahng A, Maricic I, Aguilera C, Cardell S, Halder RC, Kumar V. Prevention of autoimmunity by targeting a distinct, noninvariant CD1d-reactive $\mathrm{T}$ cell population reactive to sulfatide. J Exp Med (2004) 199(7):947-57. doi:10.1084/ jem.20031389

43. Kronenberg M. Toward an understanding of NKT cell biology: progress and paradoxes. Annu Rev Immunol (2005) 23:877-900. doi:10.1146/annurev. immunol.23.021704.115742

44. Bendelac A, Savage PB, Teyton L. The biology of NKT cells. Annu Rev Immunol (2007) 25:297-336. doi:10.1146/annurev.immunol.25.022106.141711

45. Stetson DB, Mohrs M, Reinhardt RL, Baron JL, Wang ZE, Gapin L, et al. Constitutive cytokine mRNAs mark natural killer (NK) and NK T cells poised for rapid effector function. J Exp Med (2003) 198(7):1069-76. doi:10.1084/jem. 20030630

46. Van Kaer L, Parekh VV, Wu L. Invariant natural killer T cells as sensors and managers of inflammation. Trends Immunol (2013) 34(2):50-8. doi:10.1016/j. it.2012.08.009 
47. Brigl M, Bry L, Kent SC, Gumperz JE, Brenner MB. Mechanism of CD1drestricted natural killer $\mathrm{T}$ cell activation during microbial infection. Nat Immunol (2003) 4(12):1230-7. doi:10.1038/ni1002

48. Mattner J, DeBord KL, Ismail N, Goff RD, Cantu C, Zhou DP, et al. Exogenous and endogenous glycolipid antigens activate NKT cells during microbial infections. Nature (2005) 434(7032):525-9. doi:10.1038/nature03408

49. Kinjo Y, Wu D, Kim GS, Xing GW, Poles MA, Ho DD, et al. Recognition of bacterial glycosphingolipids by natural killer T cells. Nature (2005) 434(7032):520-5. doi:10.1038/nature03407

50. Ambrosino E, Berzofsky JA, Terabe M. Regulation of tumor immunity: the role of NKT cells. Expert Opin Biol Ther (2008) 8(6):725-34. doi:10.1517/ 14712598.8.6.725

51. Metelitsa LS. Anti-tumor potential of type-I NKT cells against CD1d-positive and CD1d-negative tumors in humans. Clin Immunol (2011) 140(2):119-29. doi:10.1016/j.clim.2010.10.005

52. Balato A, Unutmaz D, Gaspari AA. Natural killer T cells: an unconventional T-cell subset with diverse effector and regulatory functions. J Invest Dermatol (2009) 129(7):1628-42. doi:10.1038/jid.2009.30

53. Van Kaer $\mathrm{L}$. Natural killer $\mathrm{T}$ cells as targets for immunotherapy of autoimmune diseases. Immunol Cell Biol (2004) 82(3):315-22. doi:10.1111/j.0818-9641. 2004.01252.x

54. Coquet JM, Kyparissoudis K, Pellicci DG, Besra G, Berzins SP, Smyth MJ, et al. IL-21 is produced by NKT cells and modulates NKT cell activation and cytokine production. J Immunol (2007) 178(5):2827-34. doi:10.4049/ jimmunol.178.5.2827

55. Sakuishi K, Oki S, Araki M, Porcelli SA, Miyake S, Yamamura T. Invariant NKT cells biased for IL-5 production act as crucial regulators of inflammation. J Immunol (2007) 179(6):3452-62. doi:10.4049/jimmunol.179.6.3452

56. Yu KO, Im JS, Molano A, Dutronc Y, Illarionov PA, Forestier C, et al. Modulation of CD1d-restricted NKT cell responses by using N-acyl variants of alpha-galactosylceramides. Proc Natl Acad Sci U S A (2005) 102(9):3383-8. doi:10.1073/pnas.0407488102

57. Sullivan BA, Nagarajan NA, Wingender G, Wang J, Scott I, Tsuji M, et al. Mechanisms for glycolipid antigen-driven cytokine polarization by Valpha14i NKT cells. J Immunol (2010) 184(1):141-53. doi:10.4049/jimmunol.0902880

58. Im JS, Arora P, Bricard G, Molano A, Venkataswamy MM, Baine I, et al. Kinetics and cellular site of glycolipid loading control the outcome of natural killer T cell activation. Immunity (2009) 30(6):888-98. doi:10.1016/j.immuni. 2009.03.022

59. Bai L, Constantinides MG, Thomas SY, Reboulet R, Meng F, Koentgen F, et al. Distinct APCs explain the cytokine bias of alpha-galactosylceramide variants in vivo. J Immunol (2012) 188(7):3053-61. doi:10.4049/jimmunol.1102414

60. Fujii S, Shimizu K, Kronenberg M, Steinman RM. Prolonged IFN-gammaproducing NKT response induced with alpha-galactosylceramide-loaded DCs. Nat Immunol (2002) 3(9):867-74. doi:10.1038/ni827

61. Buechel HM, Stradner MH, D'Cruz LM. Stages versus subsets: invariant natural killer T cell lineage differentiation. Cytokine (2015) 72(2):204-9. doi:10. 1016/j.cyto.2014.12.005

62. Barral P, Polzella P, Bruckbauer A, van Rooijen N, Besra GS, Cerundolo V, et al. CD169(+) macrophages present lipid antigens to mediate early activation of iNKT cells in lymph nodes. Nat Immunol (2010) 11(4):303-12. doi:10.1038/ ni. 1853

63. Abe T, Fujimori T. Reporter mouse lines for fluorescence imaging. Dev Growth Differ (2013) 55(4):390-405. doi:10.1111/dgd.12062

64. Johnston B, Kim CH, Soler D, Emoto M, Butcher EC. Differential chemokine responses and homing patterns of murine TCR alpha beta NKT cell subsets. J Immunol (2003) 171(6):2960-9. doi:10.4049/jimmunol.171.6.2960

65. Germanov E, Veinotte L, Cullen R, Chamberlain E, Butcher EC, Johnston B. Critical role for the chemokine receptor CXCR6 in homeostasis and activation of CD1d-restricted NKT cells. J Immunol (2008) 181(1):81-91. doi:10.4049/ jimmunol.181.1.81

66. Kim CH, Butcher EC, Johnston B. Distinct subsets of human Valpha24invariant NKT cells: cytokine responses and chemokine receptor expression. Trends Immunol (2002) 23(11):516-9. doi:10.1016/S1471-4906(02)02323-2

67. Geissmann F, Cameron TO, Sidobre S, Manlongat N, Kronenberg M, Briskin MJ, et al. Intravascular immune surveillance by CXCR6+ NKT cells patrolling liver sinusoids. PLoS Biol (2005) 3(4):e113. doi:10.1371/journal.pbio.0030113

68. Phillipson M, Kubes P. The neutrophil in vascular inflammation. Nat Med (2011) 17(11):1381-90. doi:10.1038/nm.2514
69. Thomas SY, Scanlon ST, Griewank KG, Constantinides MG, Savage AK, Barr $\mathrm{KA}$, et al. PLZF induces an intravascular surveillance program mediated by long-lived LFA-1-ICAM-1 interactions. J Exp Med (2011) 208(6):1179-88. doi:10.1084/jem.20102630

70. Emoto M, Mittrucker HW, Schmits R, Mak TW, Kaufmann SH. Critical role of leukocyte function-associated antigen-1 in liver accumulation of CD4+NKT cells. J Immunol (1999) 162(9):5094-8.

71. Wong $\mathrm{CH}$, Kubes P. Imaging natural killer T cells in action. Immunol Cell Biol (2013) 91(4):304-10. doi:10.1038/icb.2013.6

72. Dustin ML, Bromley SK, Kan Z, Peterson DA, Unanue ER. Antigen receptor engagement delivers a stop signal to migrating T lymphocytes. Proc Natl Acad Sci U S A (1997) 94(8):3909-13. doi:10.1073/pnas.94.8.3909

73. Munoz MA, Biro $M$, Weninger $W$. $T$ cell migration in intact lymph nodes in vivo. Curr Opin Cell Biol (2014) 30:17-24. doi:10.1016/j.ceb.2014.05.002

74. Velazquez P, Cameron TO, Kinjo Y, Nagarajan N, Kronenberg M, Dustin ML. Activation by innate cytokines or microbial antigens can cause arrest of natural killer T cell patrolling of liver sinusoids. J Immunol (2008) 180(4):2024-8. doi:10.4049/jimmunol.180.4.2024

75. Minagawa M, Oya H, Yamamoto S, Shimizu T, Bannai M, Kawamura H, et al. Intensive expansion of natural killer T cells in the early phase of hepatocyte regeneration after partial hepatectomy in mice and its association with sympathetic nerve activation. Hepatology (2000) 31(4):907-15. doi:10.1053/ he. 2000.5850

76. Barral P, Sanchez-Nino MD, van Rooijen N, Cerundolo V, Batista FD. The location of splenic NKT cells favours their rapid activation by blood-borne antigen. EMBO J (2012) 31(10):2378-90. doi:10.1038/emboj.2012.87

77. Shekhar S, Joyee AG, Gao X, Peng Y, Wang S, Yang J, et al. Invariant natural killer $\mathrm{T}$ cells promote $\mathrm{T}$ cell immunity by modulating the function of lung dendritic cells during Chlamydia Pneumoniae infection. J Innate Immun (2014) 7(3):260-74. doi:10.1159/000368779

78. Lee WY, Sanz MJ, Wong CHY, Hardy PO, Salman-Dilgimen A, Moriarty $\mathrm{TJ}$, et al. Invariant natural killer $\mathrm{T}$ cells act as an extravascular cytotoxic barrier for joint-invading lyme Borrelia. Proc Natl Acad Sci U S A (2014) 111(38):13936-41. doi:10.1073/pnas.1404769111

79. Kastenmuller W, Torabi-Parizi P, Subramanian N, Lammermann T, Germain RN. A spatially-organized multicellular innate immune response in lymph nodes limits systemic pathogen spread. Cell (2012) 150(6):1235-48. doi:10. 1016/j.cell.2012.07.021

80. King IL, Amiel E, Tighe M, Mohrs K, Veerapen N, Besra G, et al. The mechanism of splenic invariant NKT cell activation dictates localization in vivo. J Immunol (2013) 191(2):572-82. doi:10.4049/jimmunol.1300299

81. DeKruyff RH, Yu S, Kim HY, Umetsu DT. Innate immunity in the lung regulates the development of asthma. Immunol Rev (2014) 260(1):235-48. doi:10.1111/imr.12187

82. Scanlon ST, Thomas SY, Ferreira CM, Bai L, Krausz T, Savage PB, et al. Airborne lipid antigens mobilize resident intravascular NKT cells to induce allergic airway inflammation. J Exp Med (2011) 208(10):2113-24. doi:10.1084/ jem.20110522

83. Shimizu K, Sato Y, Shinga J, Watanabe T, Endo T, Asakura M, et al. KLRG+ invariant natural killer T cells are long-lived effectors. Proc Natl Acad Sci U S A (2014) 111(34):12474-9. doi:10.1073/pnas.1406240111

84. Kawahara K, Moll H, Knirel YA, Seydel U, Zahringer U. Structural analysis of two glycosphingolipids from the lipopolysaccharide-lacking bacterium Sphingomonas capsulata. Eur J Biochem (2000) 267(6):1837-46. doi:10.1046/j. 1432-1327.2000.01189.x

85. Dieckmann R, Graeber I, Kaesler I, Szewzyk U, von Dohren H. Rapid screening and dereplication of bacterial isolates from marine sponges of the Sula Ridge by Intact-Cell-MALDI-TOF mass spectrometry (ICM-MS). Appl Microbiol Biotechnol (2005) 67(4):539-48. doi:10.1007/ s00253-004-1812-2

86. Sriram V, Du W, Gervay-Hague J, Brutkiewicz RR. Cell wall glycosphingolipids of Sphingomonas paucimobilis are CD1d-specific ligands for NKT cells. Eur J Immunol (2005) 35(6):1692-701. doi:10.1002/eji.200526157

87. Wu D, Xing GW, Poles MA, Horowitz A, Kinjo Y, Sullivan B, et al. Bacterial glycolipids and analogs as antigens for CD1d-restricted NKT cells. Proc Natl Acad Sci U S A (2005) 102(5):1351-6. doi:10.1073/pnas.0408696102

88. Kinjo Y, Tupin E, Wu D, Fujio M, Garcia-Navarro R, Benhnia MR, et al. Natural killer T cells recognize diacylglycerol antigens from pathogenic bacteria. Nat Immunol (2006) 7(9):978-86. doi:10.1038/ni1380 
89. Kinjo Y, Illarionov P, Vela JL, Pei B, Girardi E, Li X, et al. Invariant natural killer T cells recognize glycolipids from pathogenic Gram-positive bacteria. Nat Immunol (2011) 12(10):966-74. doi:10.1038/ni.2096

90. Shapiro ED. Lyme disease. N Engl J Med (2014) 370(18):1724-31. doi:10.1056/ NEJMcp1314325

91. Biesiada G, Czepiel J, Lesniak MR, Garlicki A, Mach T. Lyme disease: review. Arch Med Sci (2012) 8(6):978-82. doi:10.5114/aoms.2012.30948

92. Crispe IN. The liver as a lymphoid organ. Annu Rev Immunol (2009) 27:147-63. doi:10.1146/annurev.immunol.021908.132629

93. Mehr S, Wood N. Streptococcus pneumoniae - a review of carriage, infection, serotype replacement and vaccination. Paediatr Respir Rev (2012) 13(4):258-64. doi:10.1016/j.prrv.2011.12.001

94. Deng X, Church D, Vanderkooi OG, Low DE, Pillai DR. Streptococcus pneumoniae infection: a Canadian perspective. Expert Rev Anti Infect Ther (2013) 11(8):781-91. doi:10.1586/14787210.2013.814831

95. Kadioglu A, Weiser JN, Paton JC, Andrew PW. The role of Streptococcus pneumoniae virulence factors in host respiratory colonization and disease. Nat Rev Microbiol (2008) 6(4):288-301. doi:10.1038/nrmicro1871

96. Kawakami K, Yamamoto N, Kinjo Y, Miyagi K, Nakasone C, Uezu K, et al. Critical role of Valpha14+ natural killer $\mathrm{T}$ cells in the innate phase of host protection against Streptococcus pneumoniae infection. Eur J Immunol (2003) 33(12):3322-30. doi:10.1002/eji.200324254

97. Chang YJ, Kim HY, Albacker LA, Lee HH, Baumgarth N, Akira S, et al. Influenza infection in suckling mice expands an NKT cell subset that protects against airway hyperreactivity. J Clin Invest (2011) 121(1):57-69. doi:10.1172/ JCI44845

98. Amprey JL, Im JS, Turco SJ, Murray HW, Illarionov PA, Besra GS, et al. A subset of liver NK T cells is activated during Leishmania donovani infection by CD1d-bound lipophosphoglycan. J Exp Med (2004) 200(7):895-904. doi:10. 1084/jem.20040704

99. Lotter H, Gonzalez-Roldan N, Lindner B, Winau F, Isibasi A, Moreno-Lafont $\mathrm{M}$, et al. Natural killer T cells activated by a lipopeptidophosphoglycan from Entamoeba histolytica are critically important to control amebic liver abscess. PLoS Pathog (2009) 5(5):e1000434. doi:10.1371/journal.ppat.1000434

100. Chen GY, Nunez G. Sterile inflammation: sensing and reacting to damage. Nat Rev Immunol (2010) 10(12):826-37. doi:10.1038/nri2873

101. Kono H, Rock KL. How dying cells alert the immune system to danger. Nat Rev Immunol (2008) 8(4):279-89. doi:10.1038/nri2215
102. Rock KL, Latz E, Ontiveros F, Kono H. The sterile inflammatory response. Annu Rev Immunol (2010) 28:321-42. doi:10.1146/ annurev-immunol-030409-101311

103. Gapin L. iNKT cell autoreactivity: what is 'self' and how is it recognized? Nat Rev Immunol (2010) 10(4):272-7. doi:10.1038/nri2743

104. Ilan Y. Alpha versus beta: are we on the way to resolve the mystery as to which is the endogenous ligand for natural killer T cells? Clin Exp Immunol (2009) 158(3):300-7. doi:10.1111/j.1365-2249.2009.04030.x

105. Godfrey DI, Pellicci DG, Rossjohn J. Beta-testing NKT cell self-reactivity. Nat Immunol (2011) 12(12):1135-7. doi:10.1038/ni.2162

106. Kain L, Webb B, Anderson BL, Deng S, Holt M, Costanzo A, et al. The identification of the endogenous ligands of natural killer $\mathrm{T}$ cells reveals the presence of mammalian alpha-linked glycosylceramides. Immunity (2014) 41(4):543-54. doi:10.1016/j.immuni.2014.08.017

107. Oshima T, Sonoda KH, Nakao S, Hijioka K, Taniguchi M, Ishibashi T. Protective role for CD1d-reactive invariant natural killer T cells in cauterizationinduced corneal inflammation. Invest Ophthalmol Vis Sci (2008) 49(1):105-12. doi:10.1167/iovs.07-0284

108. Faunce DE, Gamelli RL, Choudhry MA, Kovacs EJ. A role for CD1d-restricted NKT cells in injury-associated T cell suppression. J Leukoc Biol (2003) 73(6):747-55. doi:10.1189/jlb.1102540

109. Chamorro A, Urra X, Planas AM. Infection after acute ischemic stroke: a manifestation of brain-induced immunodepression. Stroke (2007) 38(3):1097-103. doi:10.1161/01.STR.0000258346.68966.9d

110. Westendorp WF, Nederkoorn PJ, Vermeij JD, Dijkgraaf MG, van de Beek D. Post-stroke infection: a systematic review and meta-analysis. BMC Neurol (2011) 11:110. doi:10.1186/1471-2377-11-110

Conflict of Interest Statement: The authors declare that the research was conducted in the absence of any commercial or financial relationships that could be construed as a potential conflict of interest.

Copyright $(2015$ Liew and Kubes. This is an open-access article distributed under the terms of the Creative Commons Attribution License (CC BY). The use, distribution or reproduction in other forums is permitted, provided the original author(s) or licensor are credited and that the original publication in this journal is cited, in accordance with accepted academic practice. No use, distribution or reproduction is permitted which does not comply with these terms. 